\title{
3-(2-Hydroxyethyl)-2-methylbenzothiazolium Bromide
}

\author{
Stela Minkovska ${ }^{1, *}$, Nikolay Gadjev ${ }^{2}$, Nikola Burdzhiev ${ }^{2}$, Alexi Alexiev ${ }^{2}$ and \\ Todor Deligeorgiev ${ }^{2}$ \\ 1 Institute of Catalysis, Bulgarian Academy of Sciences, Acad. G. Bonchev St, Bldg 11, 1113 Sofia, Bulgaria \\ 2 Faculty of Chemistry and Pharmacy, Sofia University “St. Kliment Ohridski”, 1, blv. J. Bourchier, \\ 1164 Sofia, Bulgaria; nigadjev@abv.bg (N.G.); ohnb@chem.uni-sofia.bg (N.B.); \\ ohaa@chem.uni-sofia.bg (A.A.); toddel@chem.uni-sofia.bg (T.D.) \\ * Correspondence: stelamin@ic.bas.bg; Tel.: +359-2-979-35-76
}

Academic Editor: Norbert Haider

Received: 24 October 2016; Accepted: 5 December 2016; Published: 9 December 2016

Abstract: A novel method for the preparation of 3-(2-hydroxyethyl)-2-methylbenzothiazolium bromide was developed. It consists of heating of 2-methylbenzothiazole, 2-bromoethanol and ethoxyethanol for $2 \mathrm{~h}$. On the next day the precipitate was filtered and air dried.

Keywords: 2-methylbenzothiazole; 2-bromoethanol; 3-(2-hydroxyethyl)-2-methylbenzo-thiazoli-um bromide

\section{Introduction}

Very few papers in English were found in the literature that deal with the synthesis of 3-(2-hydroxyethyl)-2-methylbenzothiazolium bromide 3 or iodide [1,2]. The rest of the references found were in Chinese or Japanese [3-5] or related to the patent literature [6-8] and thus were relatively inaccessible. The preparation of 3 with a reaction time of less than $2 \mathrm{~h}$ has only been reported once, but in that reference the proposed method required special conditions and MW system [1]. 3-(2-Hydroxyeth-yl)-2-methylbenzothiazolium bromide is a useful compound. It has been shown that this derivative, which incorporates a benzothiazole subunit, exhibits very high static first hyperpolarizability values in the acido-generated form [2]. This compound is a typical intermediate for the preparation of cyanine dyes $[1,2,8]$ which have different applications in the preparation of, for example, styryl dyes [2], or squaraine dyes [5,6]. The usual synthetic method requires heating for up to $18 \mathrm{~h}$ [8]. However, we have found that 3 can be obtained in a shorter time by heating for only $2 \mathrm{~h}$ (Scheme 1 ).
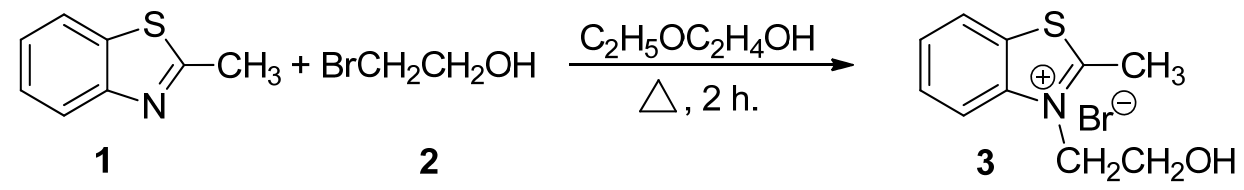

Scheme 1. Preparation of 3-(2-hydroxyethyl)-2-methylbenzothiazolium bromide 3 by quaternization with 2-bromoethanol 2.

The structure of 3-(2-hydroxyethyl)-2-methylbenzothiazolium bromide was confirmed by NMR spectra (See Supplementary Materials). 


\section{Experimental Section}

\subsection{Materials}

Unless otherwise stated, all reagents and solvents used in the synthesis and analysis were obtained from Sigma-Aldrich (St. Louis, MO, USA), Alfa-Aesar (Haverhill, MA, USA), as commercial products of analytical grade, and used without further purification.

\subsection{Instrumentation}

${ }^{1} \mathrm{H}-\mathrm{NMR}$ spectrum were recorded on a Bruker Avance III $500 \mathrm{MHz}$ (Rheinstetten, Germany) using DMSO- $d_{6}$ at room temperature. Chemical shifts $(\delta)$ are reported in ppm and referenced indirectly to the corresponding shift of the deuterated solvent peak. The melting point temperatures were determined on a Kofler bench apparatus (DDR, Berlin, Germany) and are uncorrected.

\subsection{Experimental Procedure for the Preparation of 3-(2-hydroxyethyl)-2-methylbenzothiazolium Bromid}

A $250 \mathrm{~mL}$ Erlenmeyer flask was charged with 2-methylbenzothiazole 1 (12.70 mL, $0.1 \mathrm{~mol})$, 2-bromoethanol $2(10.00 \mathrm{~mL}, 0.14 \mathrm{~mol})$, and $15 \mathrm{~mL}$ ethoxyethanol. The reaction mixture was heated under reflux and stirred for $120 \mathrm{~min}$. The reaction mixture was cooled down to room temperature and left at room temperature for $24 \mathrm{~h}$. On the next day the precipitate of 3 was filtered off and air dried. The compound was recrystallized from methanol/ethylacetate with charcoal. The crude yield of 3 was $80 \%$. The pure product for 3-(2-hydroxy-ethyl)-2-methylbenzothiazolium bromide had a melting point 166-168 ${ }^{\circ} \mathrm{C}$ (methanol/ethyl acetate)— lit. m.p.178 ${ }^{\circ} \mathrm{C}[2]$.

3-(2-Hydroxyethyl)-2-methylbenzothiazolium Bromide $5{ }^{1} \mathrm{H}-\mathrm{NMR}\left(\mathrm{DMSO}-d_{6}\right) \delta(\mathrm{ppm}): 3.24\left(\mathrm{~s}, 3 \mathrm{H}, \mathrm{C} \mathbf{H}_{3}\right)$; $3.89\left(\mathrm{t}, 2 \mathrm{H}, \mathrm{CH}_{2} \mathrm{OH}, J=5.0 \mathrm{~Hz}\right) ; 4.87\left(\mathrm{t}, 2 \mathrm{H}, \mathrm{CH}_{2} \mathrm{~N}, J=5.0 \mathrm{~Hz}\right) ; 5.23$ (br.s, $\left.1 \mathrm{H}, \mathrm{OH}\right) ; 7.80$ (t, 1H, H-Ph, $J=7.6 \mathrm{~Hz}) ; 7.87(\mathrm{t}, 1 \mathrm{H}, \mathrm{H}-\mathrm{Ph}, J=7.6 \mathrm{~Hz}) ; 8.34(\mathrm{~d}, 1 \mathrm{H}, \mathrm{H}-\mathrm{Ph}, J=8.3 \mathrm{~Hz}) ; 8.47(\mathrm{~d}, 1 \mathrm{H}, \mathrm{H}-\mathrm{Ph}, J=8.3 \mathrm{~Hz})$; ${ }^{13} \mathrm{C}-\mathrm{NMR}\left(\mathrm{DMSO}-d_{6}\right) \delta(\mathrm{ppm}): 17.41\left(1 \mathrm{C}, \mathrm{CH}_{3}\right) ; 51.99\left(1 \mathrm{C}, \mathrm{CH}_{2} \mathrm{~N}\right) ; 58.53\left(1 \mathrm{C}, \mathrm{CH}_{2} \mathrm{OH}\right) ; 117.13(1 \mathrm{C}, \mathrm{Ph})$; 124.61 (1C, Ph); 128.03 (1C, Ph); 129.01 (1C, Ph); 129.22 (1C, Ph); 141.11 (1C, Ph); 178.03 (1C, NCS).

Supplementary Materials: The following are available online at www.mdpi.com/1422-8599/2016/4/M920.

Acknowledgments: All sources of funding of the study should be disclosed. Please clearly indicate grants that you have received in support of your research work. Clearly state if you received funds for covering the costs to publish in open access.

Author Contributions: The listed authors contributed to this work as follows: T.D. contributed to the synthetic approach and together with N.G. carried out the described method. N.G. recrystallized the compounds, S.M. and A.A. prepared the manuscript. N.B. acquired and assigned the ${ }^{1} \mathrm{H}$ - and ${ }^{13} \mathrm{C}-\mathrm{NMR}$ spectra. All authors read and approve the final manuscript.

Conflicts of Interest: The authors declare no conflict of interest.

\section{References}

1. Winstead, A.J.; Fleming, N.; Hart, K.; Toney, D. Microwave Synthesis of Quaternary Ammonium Salts. Molecules 2008, 13, 2107-2113. [CrossRef] [PubMed]

2. Mançois, F.; Sanguinet, L.; Pozzo, J.-L.; Guillaume, M.; Champagne, B.; Rodriguez, V.; Adamietz, F.; Ducasse, L.; Castet, F. Acido-triggered nonlinear optical switches: Benzazolo-oxazolidines. J. Phys. Chem. B 2007, 111, 9795-9802. [CrossRef] [PubMed]

3. Wang, H.-M. Confirmation of structure of 2-substituted benzothiazole derivatives. Huaxue Yu Nianhe 2007, 29, 296-301.

4. Ye, C.-P.; Ren, J.-Q.; Ge, H.-Q.; Lu, X.-H. Synthesis of 2-substituted benzothiazoline derivatives. Hecheng Huaxue 2005, 13, 206-207.

5. Hyodo, Y.; Yagi, S.; Kitayama, H.; Nakazumi, H. Synthesis of polymer liquid crystals containing squarylium dyes. Shikizai Kyokaishi 2003, 76, 3-8. [CrossRef]

6. Li, Z.G.; Wu, C.H.; Xu, S. Preparation of squaraine chemical sensor for colorimetric identification of Fe and Cu ions. CN Patent 103172590, 26 June 2013. 
7. Inagaki, Y. Methine compounds and manufacture thereof. JP Patent 08043979, 16 February 1996.

8. Gupta, R.; Lee, S.Y.; Shen, G.-Y.; Szydlo, G.S.; Deka, C. Dyes and methods of detection of nucleic acid in immature red blood cells. U.S. Patent 20020037589, 28 March 2002.

(c)

(C) 2016 by the authors; licensee MDPI, Basel, Switzerland. This article is an open access article distributed under the terms and conditions of the Creative Commons Attribution (CC-BY) license (http:/ / creativecommons.org/licenses/by/4.0/). 